\title{
Renal AML Surgically Treated 33 Cases
}

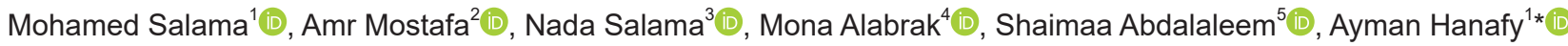 \\ ${ }^{1}$ Department of Surgical Oncology, National Cancer Institute, Cairo University, Giza, Egypt; ${ }^{2}$ Department of Urology, Kasr El-Aini, \\ Cairo University, Giza, Egypt; ${ }^{3}$ Department of Radiology, National Cancer Institute, Cairo University, Giza, Egypt; ${ }^{4}$ Department \\ of Pathology, National Cancer Institute, Cairo University, Giza, Egypt; ${ }^{5}$ Department of Biostatistics and Epidemiology, National \\ Cancer Institute, Cairo University, Giza, Egypt
}

Edited by: Ksenija Bogoeva-Kostovska Citation: Salama M, Mostafa A, Salama N, Alabrak M Abdalgeleel S, Hanafy A. Renal AML Surgically Treated 33 Cases. Open-Access Maced J Med Sci. 2022 Jan 03 Keywords: Renal angiomyolipoma: Renal mass; Keywords. Renal angiomyolipoma; Renal mass; *Correspondence: Ayman Hanafy, Department of Surgical Oncology, National Cancer Institute, Cairo University, Egypt E-mail: aymanabdelhamidelhanafy@gmail.com Received: 14-Sep-202 Revised: $17-$ Nov-2021 Accepted: 11-Dec-2021
Copyright: $\odot 2022$ Mohamed Salama, Amr Mostafa Nada Salama, Mona Alabrak, Shaimaa Abdalaleem, Funding: This research did not receive any financial Competing Interest: The authors have declared that no competing interest exists Open Access: This is an open-access article distribute under the terms of the Creative Commons AttributionNonCommercial 4.0 International License (CC BY-NC 4.0)

\begin{abstract}
BACKGROUND: Renal angiomyolipoma (RAML) is a rare benign neoplasm with a prevalence varying between $0.2 \%$ and $0.6 \%$ and a strong female predilection. They occur as sporadic, isolated entities in $80 \%$ of cases. The remaining $20 \%$ of angiomyolipomas (AMLs) develop in association with tuberous sclerosis complex or pulmonary lymphangioleiomyomatosis.

AIM: We describe our 10-year experience with AML and discuss the treatment strategies employed at our center

METHODS: The medical records of all 33 patients with pathologically confirmed RAML treated either by nephrectomy or nephron-sparing surgery at our center over 10 years were reviewed for patient age and sex, tumor location and size, association with TBS.

RESULTS: There were 28 females $(84.8 \%)$ and 5 males $(15.2 \%)$ with a median age that was 52 (range 22-74) years at the time of surgery. Thirty patients $(90.9 \%)$ had sporadic isolated AML, and 3 patients $(9.1 \%)$ had AML with TBS. The tumor was in the right kidney in 15 (45.5\%) patients, in the left kidney in $17(51.5 \%)$ patients, and bilateral in only 1 patient (3\%) who was diagnosed with TBS. At presentation, flank pain was the main symptom in 23 patients $(69.7 \%)$.

CONCLUSIONS: Surgical resection of RAML provides short-term symptomatic relieve and long-term survival.
\end{abstract}

\section{Introduction}

Renal angiomyolipoma (RAML) is an uncommon benign tumor with a female predisposition and a frequency ranging from $0.2 \%$ to $0.6 \%$. In $80 \%$ of cases, they appear as sporadic, isolated entities. Tuberous sclerosis complex or pulmonary lymphangioleiomyomatosis are responsible for the remaining $20 \%$ of angiomyolipomas (AMLs) [1], [2]. Smooth muscle cells, adipose tissue, and blood vessels are among the three mesenchymal constituents that make up the mesenchyme [3].

The majority of RAML patients are asymptomatic and are identified by chance during an abdominal ultrasound or computed tomography (CT) scan [4].

The most common clinical characteristic is still pain. The majority of the other symptoms are produced by spontaneous bleeding in the tumor, which is caused by the high vascularization, stiffness, and inelasticity, and tortuosity of the blood vessels, which can lead to retroperitoneal bleeding and shock [5].

Oesterling et al. [6] have redesigned RAML treatment by suggesting a systematic approach based on tumor size and symptoms. Symptomatic tumors greater than $4 \mathrm{~cm}$ should be angiographically investigated and treated with embolization or nephronpreserving surgery.

Because RAML is benign, it is an ideal tumor for nephron-sparing treatment such as tumor enucleation, partial nephrectomy, or selective arterial embolization. However, because data on organ preservation surgery in RAML are limited, patients have continued to be treated with nephrectomy [7], [8].

We describe our 10-year experience with AML and discuss the treatment strategies employed at our center.

\section{Patients and Methods}

All 33 individuals with pathologically confirmed RAML had their medical records reviewed. Over the course of 10 years, these patients were treated at our center by either nephrectomy or nephron-sparing surgery (NSS), and their records were evaluated for patient age and sex, tumor location and size, and TBS association. The Gomez criteria were used to diagnose TBS [9]. 
All patients were evaluated for signs and symptoms of RAML such as flank pain, hemorrhage, abdominal distension, nausea, vomiting, and anemia. Pre- and post-operative renal function was investigated by the measurements of serum creatinine and urea concentrations. In addition, CT, or magnetic resonance imaging (MRI), and/or ultrasonographic findings of RAML were reviewed to reevaluate the specific morphology of the tumors.

Follow-up investigations consisted of regular ultrasonographic and CT investigations. Usually, the first CT scan was performed 3 months postoperatively; further evaluation of both kidneys or the remaining one was done by serial ultrasonography with CT scans being only performed in case of significant morphological changes of the kidney. The patients were followed up for a median period of 6 years, ranging from 3 to 15 years. Statistical analysis was performed using Wilcoxon's signed-rank test to compare differences in the pre- and post-operative results.

\section{Results}

All patients with pathologically confirmed RAML who underwent either NSS or nephrectomy were retrospectively reviewed. Table 1 summarizes the characteristics of the patients regarding age, gender, tumor location, tumor size, operative details, and follow-up.

There were 28 females (84.8\%) and 5 males $(15.2 \%)$ with a median age that was 52 (range $22-74$ ) years at the time of surgery. Thirty patients $(90.9 \%)$ had sporadic isolated AML, and 3 patients $(9.1 \%)$ had $A M L$ with TBS (Figure 1). The tumor was in the right kidney in $15(45.5 \%)$ patients, in the left kidney in $17(51.5 \%)$ patients, and bilateral in only 1 patient (3\%) who was diagnosed with TBS (Figure 2). At presentation, flank pain was the main symptom in 23 patients $(69.7 \%)$, abdominal mass in three patients, bleeding in 3 patients $(9.1 \%)$, and incidentally discovered in 7 patients $(21.2 \%)$.

Using ultrasound, CT, or MRI failed to establish the RAML diagnosis in six RAML patients (four as retroperitoneal liposarcoma and two as renal cell carcinoma). However, RAML was diagnosed in 27 patients using the investigation mentioned above. The mean maximum tumor diameter was $12.2 \mathrm{~cm}$. The lower pole of the kidney was affected by the tumor in 15 patients $(45.5 \%)$, the upper pole in 12 patients $(36.4 \%)$, central in 5 patients $(15.2 \%)$, and one arising from the lateral border of the kidney (3\%).
Table 1: Perioperative characteristics

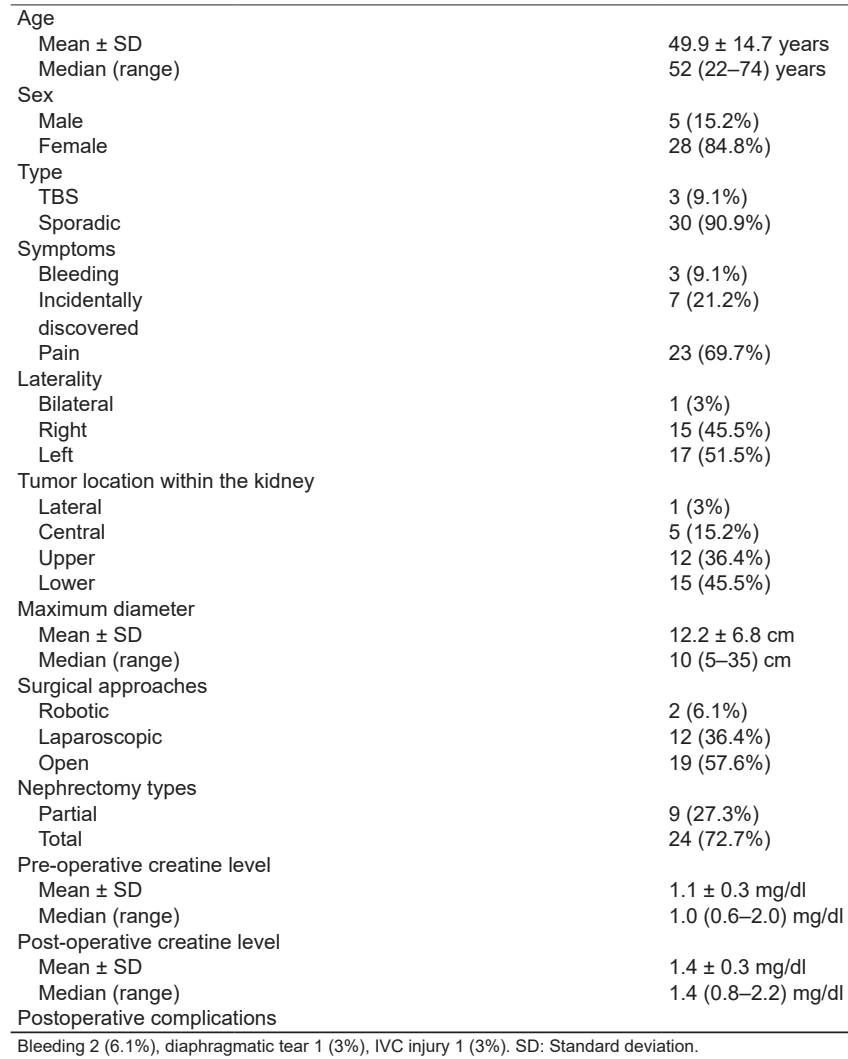

Total nephrectomy was done for 24 patients $(72.7 \%)$ (Figure 3$)$, nephron-preserving surgery was performed in 9 patients (27.3\%). Nineteen patients were conducted through an open surgical approach (57.6\%). Twelve patients were performed with laparoscopy (36.4\%), 2 patients $(6.1 \%)$ were operated on with the aid of a robotic approach.

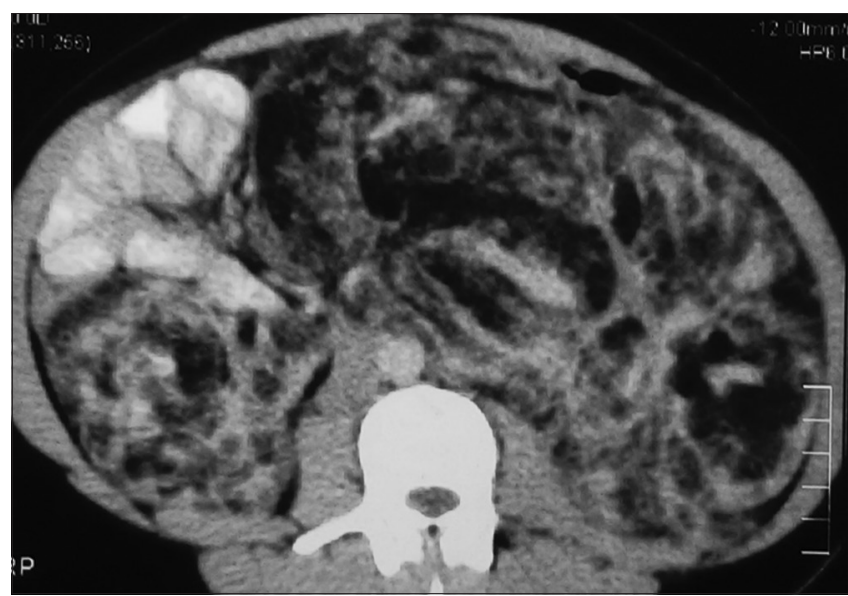

Figure 1:Pre-operative computed tomography scan of angiomyolipoma large bilateral lesions

Post-operative complications occurred in 4 patients $(12.1 \%)$ in the form of post-operative bleeding in two patients, a diaphragmatic tear in only one patient, and IVC intraoperative injury in only one patient. The mean 3-year post-operative creatinine level was $1.4 \pm 0.3 \mathrm{mg} / \mathrm{dl}$. 


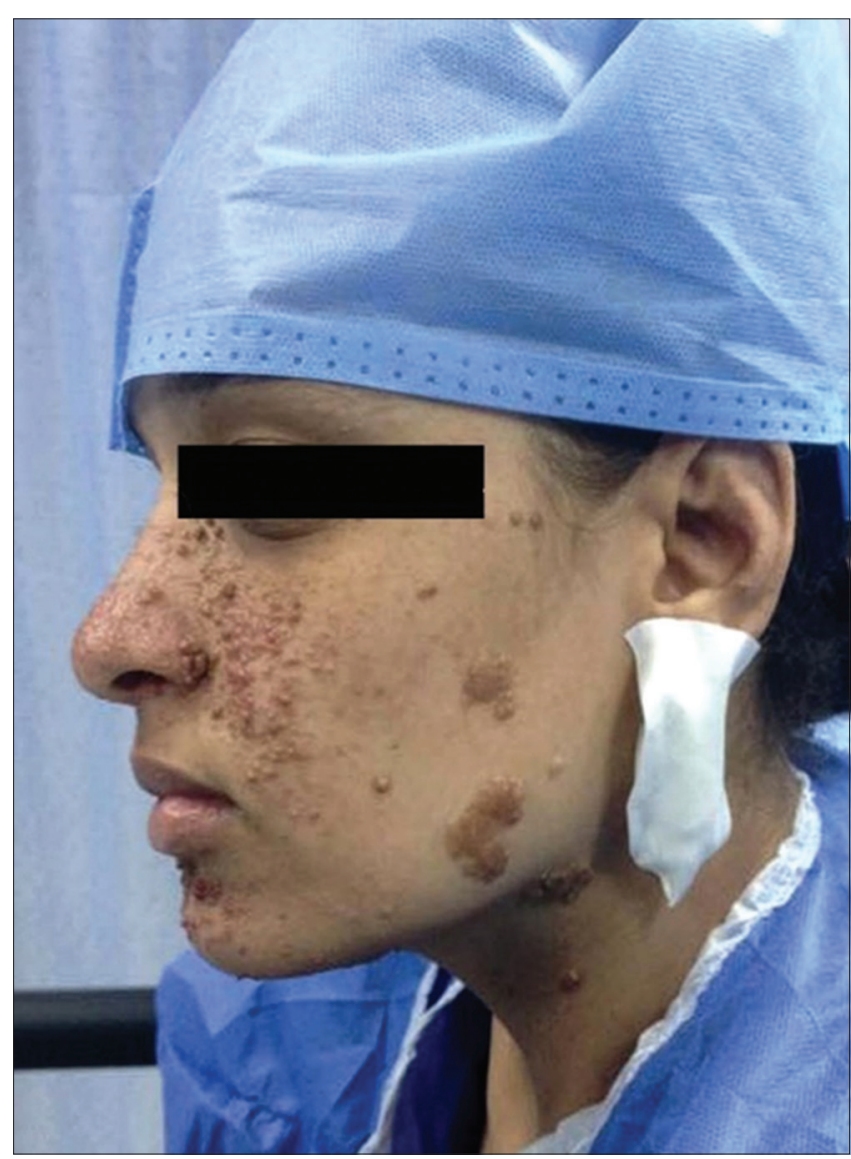

Figure 2: Skin manifestations of tuberous sclerosis

\section{Discussion}

The study presents our experience with AML. The classic RAML is one of the kidney's most common benign renal lesions, consisting of $2.0-6.4 \%$ of all kidney tumors and about $1 \%$ of surgically removed renal tumors [10], [11], [12].

In the present study, the patients were in the fourth to sixth decades of life, with a mean age of 49.9 years, similar to previously reported [13], [14]. About $80 \%$ of RAMLs occur primarily in women between the $4^{\text {th }}$ and $7^{\text {th }}$ decade of life and develop spontaneously regardless of TS [15], as demonstrated in the present study (female: male $=85 \%: 15 \%$ ). The increasing incidence in women may be partly due to hormonal differences. Angiomyolipomata typically expresses receptors for both estrogen and progesterone [16]. In contrast, renal AMLs associated with TS most often occur at a younger age (two patients 28 and one 56 years), bilaterally (in one of three patients) developed and frequently symptomatic large-sized lesion.

The tumor was unilateral in $97 \%$ of patients (45.5\% in the right and $51.5 \%$ in the left kidney), and only one patient had TBS had bilateral RAML (Figure 1). Patients presented with flank pain $(69.7 \%)$, abdominal mass $(9.1 \%)$, bleeding $(9.1 \%)$, and $(21.2 \%)$ of the patients, the RAML has detected accidentally. These presentations frequencies are similar to the clinical manifestations reported earlier [17].

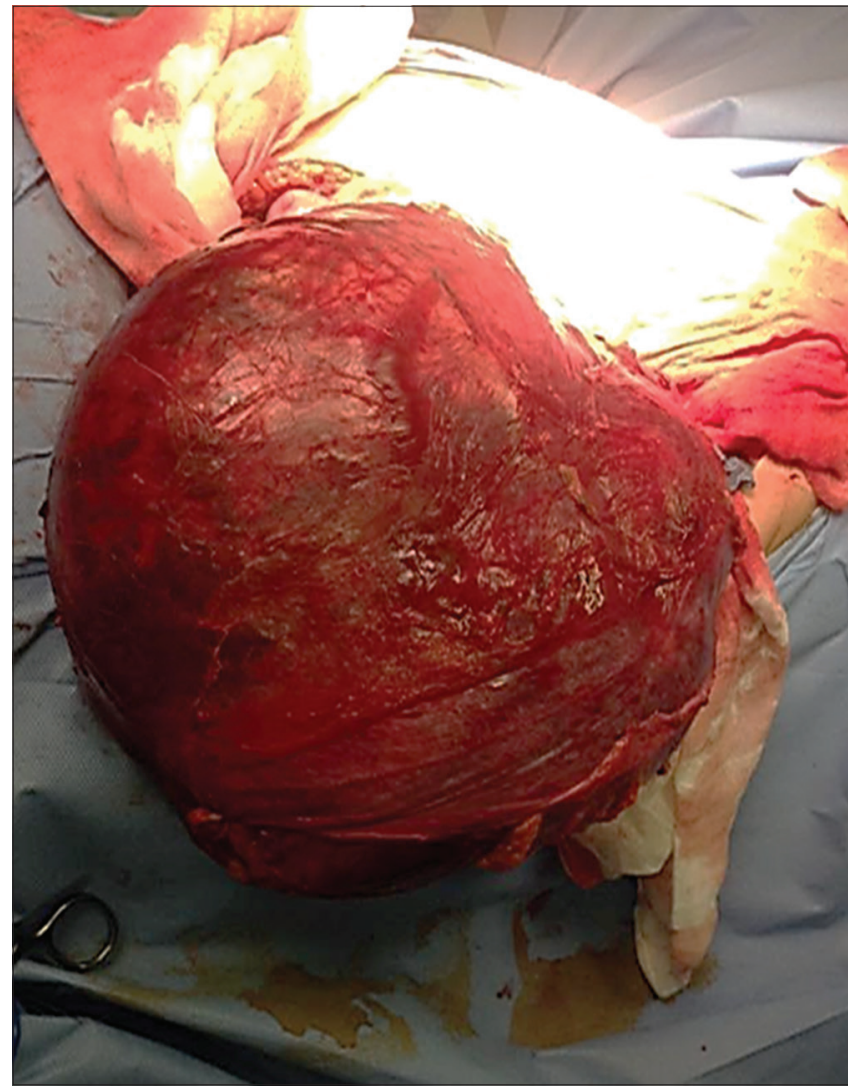

Figure 3: Total nephrectomy in angiomyolipoma patient

Yamakado et al. reported that significant relationships between the size of the tumor and rupture in AMLs are the main predictor of bleeding. In the present study, a small-sized tumor as $5 \mathrm{~cm}$ was presented with pain, abdominal mass in seven patients [17].

In RAML, surgical interventions are indicated to relieve pain or bleeding symptoms or establish a diagnosis when the lesion has a high suspicion of carcinoma [18]. Moreover, although surgical excision by either partial or radical nephrectomy is the only treatment that improves patients' complaints, the recurrence rate is high [19].

In RAML, surgery is indicated to relieve pain or bleeding symptoms or diagnose if the lesion is strongly suspected to be carcinoma [20]. Although surgical excision by partial or radical nephrectomy is the only treatment that improves patient discomfort, the recurrence rate is high [21]. Total renal excision is only recommended for rescuing patients if the RAML is very large, there is a high suspicion of malignancy, or other therapeutic approaches are not visible [22], [23]. In this study, in cases of misdiagnosis operated with a nephron-protective surgical procedure, complete kidney removal was performed in approximately $76 \%$ of the cases. Nevertheless, some authors advocate a nephron-sparing operation to obtain an accurate histological diagnosis regardless of the tumor size. Total nephrectomy was performed in 24 patients $(72.7 \%)$ because of the size, central location of the 
tumor, and the difficulty of making a diagnosis before surgery [24], [25].

\section{Conclusions}

Surgical resection of RAML provides shortterm symptomatic relieve and long-term survival.

\section{References}

1. Fittschen A, Wendlik I, Oeztuerk S, Kratzer W, Akinli AS, Haenle MM, et al. Prevalence of sporadic renal angiomyolipoma: A retrospective analysis of 61,389 in-and out-patients. Abdom Imaging. 2014;39(5):1009-13. https://doi.org/10.1007/ s00261-014-0129-6

PMid:24705668

2. Flum AS, Hamoui N, Said MA, Yang XJ, Casalino DD, McGuire BB, et al. Update on the diagnosis and management of renal angiomyolipoma. J Urol. 2016;195(4 Part 1):834-46. https://doi.org/10.1016/j.juro.2015.07.126

PMid:26612197

3. Song X, Liu Z, Cappell K, Gregory C, Said Q, Prestifilippo J, et al. Healthcare utilization and costs in patients with tuberous sclerosiscomplex-related renal angiomyolipoma. J Med Econ. 2017;20(4):388-94. https://doi.org/10.1080/13696998.2016.1272461 PMid:27998195

4. Yamamoto S, Nakamura K, Kawanami S, Aoki T, Watanabe H, Nakata H. Renal angiomyolipoma: Evolutional changes of its internal structure on CT. Abdom Imaging. 2000;25(6):651-4. https://doi.org/10.1007/s002610000051

PMid:11029101

5. van Baal JG. Angiomyolipoma Renis and its Relation to Tuberous Sclerosis; 1987.

6. Oesterling JE, Fishman EK, Goldman SM, Marshall FF. The managementofrenalangiomyolipoma.JUrol.1986;135(6):1121-4. https://doi.org/10.1016/s0022-5347(17)46013-7

\section{PMid:3520013}

7. Malone MJ, Johnson PR, Jumper BM, Howard PJ, Hopkins TB Libertino JA. Renal angiomyolipoma: 6 case reports and literature review. J Urol. 1986;135(2):349-53. https://doi. org/10.1016/s0022-5347(17)45636-9

PMid:3511290

8. Mourikis D, Chatziioannou A, Antoniou A, Kehagias D, Gikas D, Vlahos L. Selective arterial embolization in the management of symptomatic renal angiomyolipomas. Eur JRadiol. 1999;32(3):1539. https://doi.org/10.1016/s0720-048x(98)00179-x PMid:10632551

9. Gomez MR, Gomez M. Other visceral, vascular, and osseous lesions. In: Tuberous Sclerosis. New York: Raven Press; 1979. p. 171-92.

10. Lopez-Beltran A, Scarpelli M, Montironi R, Kirkali Z. 2004 WHO classification of the renal tumors of the adults. Eur Urol. 2006;49(5):798-805. https://doi.org/10.1016/j. eururo.2005.11.035 PMid: 16442207

11. Tsai CC, Wu WJ, Li CC, Wang CJ, Wu CH, Wu CC. Epithelioid angiomyolipoma of the kidney mimicking renal cell carcinoma: A clinicopathologic analysis of cases and literature review. Kaohsiung J Med Sci. 2009;25(3):133-40. https://doi. org/10.1016/s1607-551x(09)70052-x

PMid:19419918

12. He W, Cheville JC, Sadow PM, Gopalan A, Fine SW, Al-Ahmadie HA, et al. Epithelioid angiomyolipoma of the kidney: Pathological features and clinical outcome in a series of consecutively resected tumors. Mod Pathol.2013;26(10):1355-64. https://doi.org/10.1038/modpathol.2013.72 PMid:23599151

13. Yang L, Feng $X L$, Shen $S$, Shan L, Zhang HF, Liu XY, et al. Clinicopathological analysis of 156 patients with angiomyolipoma originating from different organs. Oncol Lett 2012;3:586-90. https://doi.org/10.3892/ol.2012.554 PMid:22740957

14. Katabathina VS, Vikram R, NagarAM, Tamboli P, Menias CO, Prasad SR. Mesenchymal neoplasms of the kidney in adults: Imaging spectrum with radiologic-pathologic correlation. Radiographics. 2010;30(6):1525-40. https://doi.org/10.1148/rg.306105517 PMid:21071373

15. Steiner MS, Goldman SM, Fishman EK, Marshall FF. The natura history of renal angiomyolipoma. J Urol. 1993;150(6):1782-6. https://doi.org/10.1016/s0022-5347(17)35895-0

PMid:8230504

16. Henske E, Ao X, Short MP, Greenberg R, Neumann HP Kwiatkowski DJ, et al. Frequent progesterone receptor immunoreactivity in tuberous sclerosis-associated renal angiomyolipomas. Mod Pathol. 1998;11(7):665-8. PMid:9688188

17. Yamakado $\mathrm{K}$, Tanaka $\mathrm{N}$, Nakagawa $\mathrm{T}$, Kobayashi $\mathrm{S}$, Yanagawa M, Takeda K. Renal angiomyolipoma: relationships between tumor size, aneurysm formation, and rupture. Radiology. 2002;225(1):78-82. https://doi.org/10.1148/radiol.2251011477 PMid: 12354988

18. NelsonCP,SandaMG. Contemporary diagnosisandmanagement of renal angiomyolipoma. J Urol 2002;168(4):1315-25. https:// doi.org/10.1097/01.ju.0000028200.86216.b2 PMid:12352384

19. Weber DM, Schönbucher VB, Landolt MA, Gobet R. The pediatric penile perception score: An instrument for patient self-assessment and surgeon evaluation after hypospadias repair. J Urol 2008;180:1080-4; discussion 1084. https://doi. org/10.1016/j.juro.2008.05.060

PMid:18639292

20. NelsonCP,SandaMG. Contemporary diagnosisand management of renal angiomyolipoma. J Urol. 2002;168(4):1315-25.

21. Weber DM, Schönbucher VB, Landolt MA, Gobet R. The pediatric penile perception score: An instrument for patient selfassessment and surgeon evaluation after hypospadias repair. $J$ Urol. 2008;180(3):1080-4.

22. Eijkemans MJ, van der Wal W, Reijnders LJ, Roes KC, van Waalwijk van Doorn-Khosrovani SB, Pelletier C, et al. Longterm follow-up assessing renal angiomyolipoma treatment patterns, morbidity, and mortality: An observational study in tuberous sclerosis complex patients in the Netherlands. Am J Kidney Dis. 2015;66(4):638-45.

23. Urciuoli P, D'ORAZI V, Livadoti G, Foresi E, Panunzi A, Anichin $S$, et al. Treatment of renal angiomyolipoma: Surgery versus angioembolization. G Chir. 2013;34(11-12):326.

24. Koike H, Müller S, Hohenfellner R. Management of rena angiomyolipoma: A report of 14 cases and review of the literature. Eur Urol. 1994;25:183-8.

25. Novick AC. Partial nephrectomy for renal cell carcinoma Urology. 1995;46:149-52. 